\title{
The effect of overweight on the luteinizing hormone level after gonadorelin stimulation test in girls with idiopathic central precocious puberty
}

Hyun Young Lee, MD', Yoon-Ji Lee, MD', Moon-Bae Ahn, MD', Won-Kyoung Cho, MD, PhD', Byung-Kyu Suh, MD, PhD ${ }^{1}$

'Department of Pediatrics, Seoul St. Mary's Hospital, College of Medicine, The Catholic University of Korea, Seoul, ${ }^{2}$ Department of Pediatrics, St. Vincent's Hospital, College of Medicine, The Catholic University of Korea, Suwon, Korea

Received: 18 July, 2018

Revised: 11 September, 2018

Accepted: 11 October, 2018

Address for correspondence:

Byung-Kyu Suh, MD, PhD

Department of Pediatrics, Seoul St. Mary's Hospital, College of Medicine, The Catholic University of Korea, 222 Banpo-daero, Seocho-gu, Seoul 06591, Korea

Tel: $+82-2-2258-2828$

Fax: +82-2-537-4544

E-mail: suhbk@catholic.ac.kr https://orcid.org/0000-0003-19710232

Address for co-correspondence: Won-Kyoung Cho, MD, PhD Department of Pediatrics, St. Vincent's Hospital, College of Medicine, The Catholic University of Korea, 93 Jungbu-daero, Paldal-gu, Suwon 16247, Korea

Tel: +82-31-249-8312

Fax: +82-31-249-8017

E-mail:wendy626@catholic.ac.kr

https://orcid.org/0000-0003-09180565
Purpose: We investigated the effect of overweight on luteinizing hormone (LH) levels after a gonadorelin stimulation test in Korean girls with idiopathic central precocious puberty (CPP).

Methods: Medical records of 234 girls diagnosed with idiopathic CPP were reviewed retrospectively. CPP was diagnosed when the peak LH levels after gonadorelin stimulation was $>5.0 \mathrm{U} / \mathrm{L}$. The enrolled girls had a peak $\mathrm{LH}$ level $>5.0 \mathrm{U} / \mathrm{L}$ after a gonadorelin stimulation test. Selected girls were classified as normoweight (body mass index [BMI] below the 85th percentile with respect to age) and overweight (BMI greater than the 85th percentile with respect to age).

Results: The peak LH $(8.95 \pm 2.85 \mathrm{U} / \mathrm{L}$ vs. $11.97 \pm 8.42 \mathrm{U} / \mathrm{L}, P<0.01)$ and peak folliclestimulating hormone $(9.60 \pm 2.91 \mathrm{U} / \mathrm{L}$ vs. $11.17 \pm 7.77 \mathrm{U} / \mathrm{L}, P=0.04)$ after gonadorelin stimulation were lower in overweight girls with idiopathic CPP than in normoweight girls with idiopathic CPP. Being overweight was negatively associated with peak LH levels after gonadorelin stimulation test (odds ratio, 0.89; $95 \%$ confidence interval, $0.81-0.98, P=0.02$ ).

Conclusion: In girls with idiopathic CPP, being overweight led to a lower LH peak after gonadorelin stimulation. Further research is needed to better understand the role of overweight on gonadotropin secretion in precocious puberty.

Keywords: Puberty, Metabolic disease, Obesity

\section{Introduction}

Normal puberty is initiated by central gonadal function, driven by increased gonadotropinreleasing hormone $(\mathrm{GnRH})$ and gonadotropin secretion. Central precocious puberty $(\mathrm{CPP})$ in girls results from the premature activation of the hypothalamic-pituitary-gonadal (HPG) axis, and is characterized by the onset of secondary sexual development before the chronological age (CA) of eight years. ${ }^{1)}$ In Korean girls, the incidence of CPP appears to be increasing rapidly. ${ }^{2)}$ Excessive estrogen secretion in girls with CPP may lead to advanced bone age (BA), compromised final height, accelerated menarche, as well as psychological and behavioral issues.

Childhood obesity has become a major health concern in recent decades. Obesity not only interacts with short- and long-term metabolic and cardiovascular morbidities but also affects the onset of puberty. ${ }^{3}$ Multiple studies have shown evidence of earlier onset of puberty in obese girls. A certain amount of body fat in women is essential for maintaining normal reproductive functioning; however, excessive adiposity is a risk factor for pubertal disorders. ${ }^{4)}$ Furthermore, childhood obesity and insulin resistance have been identified as predisposing factors for polycystic ovarian syndrome (PCOS). ${ }^{5.6}$

Although the underlying mechanism between excessive body weight and precocious 
puberty is not completely understood, previous studies showed an inverse correlation between body mass index (BMI) and luteinizing hormone (LH) peak among girls in the early stages of puberty. Because the elevation of LH concentration after gonadorelin stimulation is a major determinant in precocious puberty, the present study investigates the relationship of overweight on the diagnosis of precocious puberty in Korean girls.

\section{Materials and methods}

\section{Subjects}

In total, 234 girls diagnosed with idiopathic CPP between 2007 and 2016 at Seoul St. Mary's Hospital (Korea) were included. All participants were identified as expressing signs of secondary sexual development such as breast enlargement before the age of 8 . Selected individuals were classified according to their BMI: normal weight (BMI below the 85th percentile with respect to age) and overweight (BMI greater than the 85th percentile with respect to age). Any girls with previously identified endocrine disorders that accelerate pubertal progression or other causes disrupting the HPG axis were excluded. The medical records of the participants were retrospectively evaluated to obtain anthropometric and radiological data (i.e., height, weight, CA, and BA). This study was approved from the Institutional Review Board (IRB) of Seoul St. Mary's Hospital of The Catholic University of Korea and written informed consent was exempt from the IRB (approval number: KC17RCSI0762).

\section{Methods}

For measuring height, a Harpenden stadiometer (Holdtain Ltd., Crymych, Wales) was used with an increment of $0.1 \mathrm{~cm}$, while weight was measured within $0.1 \mathrm{~kg}$ using a CAS scale (CAS, Seoul, Korea). A trained technician performed the measures based on the manufacturer's guidelines including positioning. BMI calculations and all anthropometry data were used to calculate a standard deviation score ( $z$-score) based on Korean reference data. ${ }^{7}$ Tanner stage ratings I through $\mathrm{V}$ were assigned by a trained rater. Baseline $\mathrm{LH}$, folliclestimulating hormone $(\mathrm{FSH})$, and estradiol $\left(\mathrm{E}_{2}\right)$ were collected initially, and then LH and FSH were measured at 30, 45, 60, and 90 minutes after intravenous administration of 100.0 $\mu \mathrm{g}$ gonadorelin acetate (Relefact; Sanofi-Aventis, Frankfurt, Germany). CPP was diagnosed when the peak LH levels after a gonadorelin stimulation was $>5.0 \mathrm{U} / \mathrm{L}$. The basal serum $\mathrm{E}_{2}$ concentration was assayed by a radioimmunoassay (BioSource, Nivelles, Belgium); LH and FSH levels were determined with immunoradiometric assays (BioSource). BA assessment was performed by radiography of the left hand using the Greulich and Pyle method. ${ }^{8)}$

\section{Statistical analyses}

Statistical analyses were performed using SAS ver. 9.4 (SAS Institute Inc., Cary, NC, USA). Continuous variables were compared using Student $t$-test and are expressed as means \pm standard deviations. Discrete variables were compared using a chi-square test or Fisher exact test and are expressed as

Table 1. Clinical characteristics and biochemical profiles of girls with idiopathic central precocious puberty according to overweight status

\begin{tabular}{|c|c|c|c|c|}
\hline Variable & Total $(n=234)$ & Normal weight $(n=199)$ & Overweight $(n=35)$ & $P$-value \\
\hline CA (yr) & $8.44 \pm 0.46$ & $8.44 \pm 0.46$ & $8.42 \pm 0.50$ & 0.72 \\
\hline$B A(y r)$ & $10.32 \pm 0.8$ & $10.29 \pm 0.86$ & $10.50 \pm 0.84$ & 0.17 \\
\hline SMR-breast & $2.5(1.0-4.0)$ & $2.5(1.0-4.0)$ & $3.0(2.0-3.5)$ & 0.02 \\
\hline SMR-pubic hair & $1.0(1.0-2.0)$ & $1.0(1.0-2.0)$ & $1.0(1.0-1.0)$ & 0.05 \\
\hline Height & $133.27 \pm 5.01$ & $133.17 \pm 4.98$ & $133.85 \pm 5.20$ & 0.47 \\
\hline Height-SDS & $0.83 \pm 0.85$ & $0.80 \pm 0.84$ & $1.01 \pm 0.89$ & 0.19 \\
\hline Weight & $30.68 \pm 4.16$ & $29.77 \pm 3.53$ & $35.93 \pm 3.63$ & $<0.0001$ \\
\hline Weight-SDS & $0.40 \pm 0.71$ & $0.24 \pm 0.59$ & $1.38 \pm 0.57$ & $<0.0001$ \\
\hline $\mathrm{BMI}\left(\mathrm{kg} / \mathrm{m}^{2}\right)$ & $17.23 \pm 1.77$ & $16.75 \pm 1.35$ & $20.02 \pm 1.262$ & $<0.0001$ \\
\hline BMI-SDS & $0.25 \pm 0.77$ & $0.06 \pm 0.66$ & $1.35 \pm 0.33$ & $<0.0001$ \\
\hline FBS (mg/dL) & $99.48 \pm 16.22$ & $99.20 \pm 16.61$ & $101.06 \pm 13.85$ & 0.54 \\
\hline AST (U/L) & $25.61 \pm 5.19$ & $25.78 \pm 4.93$ & $24.65 \pm 6.49$ & 0.34 \\
\hline $\operatorname{ALT}(\mathrm{U} / \mathrm{L})$ & $14.50 \pm 5.38$ & $14.14 \pm 4.30$ & $16.56 \pm 9.30$ & 0.15 \\
\hline $\mathrm{TC}(\mathrm{mg} / \mathrm{dL})$ & $161.99 \pm 25.74$ & $160.40 \pm 24.52$ & $171.15 \pm 30.65$ & 0.02 \\
\hline TG (mg/dL) & $97.19 \pm 51.87$ & $94.20 \pm 53.18$ & $114.32 \pm 40.08$ & 0.04 \\
\hline $\mathrm{HDL}(\mathrm{mg} / \mathrm{dL})$ & $54.55 \pm 11.02$ & $54.23 \pm 10.51$ & $56.35 \pm 13.63$ & 0.39 \\
\hline LDL (mg/dL) & $88.01 \pm 23.29$ & $87.32 \pm 22.91$ & $91.93 \pm 25.35$ & 0.29 \\
\hline
\end{tabular}

Values are presented as mean \pm standard deviation or median (range).

CA, chronological age; BA, bone age; SMR, sexual maturity rating; SDS, standard deviation score; BMI, body mass index; FBS, fasting blood sugar; AST, aspartate transaminase; ALT, alanine transaminase; TC, total cholesterol; TG, triglyceride; HDL, high-density lipoprotein; LDL, low-density lipoprotein. 
percentages. We used a multivariate logistic regression model and only those variables that were significantly associated with excess weight were used in our univariate analyses. All analyses were 2-tailed, and clinical significance was defined as a $P$-value of $<0.05$. We also used multiple logistic regression analysis to identify factors associated with the odds ratios (ORs) and 95\% confidence interval (CI). For classification of clinical parameters according to BMI, an analysis of variance was performed with a post hoc Tukey test. To determine the significance of associations with peak LH, univariate and multivariate logistic regression analyses were performed.

\section{Results}

\section{Clinical characteristics of girls with idiopathic CPP according to overweight}

Among 234 girls with idiopathic CPP, 199 (85.0 \%) had weight in the normal range and $35(15.0 \%)$ had overweight. Their overall mean CA and BA were 8.4 and 10.3 years, respectively, and there was no significant difference between the 2 groups. Tanner stage for breast development was more advanced among overweight participants (3.0 [2.0-3.5] vs. 2.5 [1.0-4.0], $P=0.02)$. The BMI $z$-score with respect to CA was $1.35 \pm 0.33$ for overweight girls and $0.06 \pm 0.66$ for normoweight girls $(\mathrm{P}<0.01)$. Total cholesterol $(171.15 \pm 30.65 \mathrm{mg} / \mathrm{dL}$ vs. $160.40 \pm 24.52 \mathrm{mg} / \mathrm{dL}$, $P=0.02)$ and triglyceride $(114.32 \pm 40.08 \mathrm{mg} / \mathrm{dL}$ vs. $94.20 \pm 53.18$ $\mathrm{mg} / \mathrm{dL}, P=0.04)$ levels were higher in overweight group compared to normal weight group. Participant baseline clinical characteristics are shown in Table 1.

\section{Hormonal data of girls with idiopathic CPP according to overweight}

Both LH $(8.95 \pm 2.85 \mathrm{U} / \mathrm{L}$ vs. $11.97 \pm 8.42 \mathrm{U} / \mathrm{L}, P<0.01)$ and FSH peaks $(9.60 \pm 2.91 \mathrm{U} / \mathrm{L}$ vs. $11.17 \pm 7.77, P=0.04)$ were significantly higher in the normoweight group after gonadorelin stimulation $(8.95 \pm 2.84 \mathrm{U} / \mathrm{L}$ vs. $11.97 \pm 8.42 \mathrm{U} / \mathrm{L}, P<0.01$ and $9.60 \pm 2.91 \mathrm{U} /$ $\mathrm{L}$ vs. $11.17 \pm 7.77 \mathrm{U} / \mathrm{L}, P=0.04)$, and the degree of difference was more remarkable in LH than in FSH (Table 2). Basal LH, FSH, and $\mathrm{E}_{2}$ levels did not differ between the two groups. The peak $\mathrm{LH}$ to $\mathrm{FSH}$ ratio was higher in the normoweight group than in the overweight group ( $1.24 \pm 0.86$ vs. $0.99 \pm 0.38, P=0.01)$.

\section{Regression analysis of factors associated with overweight}

We performed a multiple regression analysis of the variables that affect the degree of overweight (Table 3). Overweight had a positive correlation with Tanner stage for breast development (OR, 2.8; 95\% CI, 1.3-5.9; $P=0.01$ ), whereas it had a negative correlation with peak LH levels after gonadorelin stimulation test (OR, 0.89; $95 \% \mathrm{CI}, 0.81-0.98 ; P=0.02$ ). In contrast, $\mathrm{CA}$, $\mathrm{BA}$, basal LH, basal FSH, and peak FSH showed no significant associations with overweight.

Table 2. Hormonal levels of girls with idiopathic central precocious puberty according to overweight status

\begin{tabular}{lcccc}
\hline Variable & Total $(n=234)$ & Normal weight $(n=199)$ & Overweight $(n=35)$ & $P$-value \\
\hline LH-basal & $1.17 \pm 0.71$ & $1.18 \pm 0.73$ & $1.15 \pm 0.66$ & 0.84 \\
LH-peak & $11.52 \pm 7.93$ & $11.97 \pm 8.42$ & $8.95 \pm 2.85$ & $<0.001$ \\
FSH-basal & $2.39 \pm 1.40$ & $2.39 \pm 1.40$ & $2.44 \pm 1.43$ & 0.84 \\
FSH-peak & $10.94 \pm 7.28$ & $11.17 \pm 7.77$ & $9.60 \pm 2.91$ & 0.04 \\
Estradiol & $34.27 \pm 29.96$ & $32.76 \pm 22.30$ & $43.10 \pm 56.76$ & 0.30 \\
LH-peak/FSH-peak & $1.21 \pm 0.82$ & $1.24 \pm 0.86$ & $0.99 \pm 0.38$ & 0.01 \\
\hline
\end{tabular}

Values are presented as mean \pm standard deviation.

LH, luteinizing hormone; FSH, follicle-stimulating hormone.

Table 3. Multivariate logistic regression analysis of associations with overweight

\begin{tabular}{|c|c|c|c|c|}
\hline \multirow{2}{*}{ Variable } & \multicolumn{2}{|l|}{ Univariate } & \multicolumn{2}{|c|}{ Multivariate logistic regression analysis } \\
\hline & OR $(95 \% \mathrm{Cl})$ & $P$-value & OR $(95 \% \mathrm{Cl})$ & $P$-value \\
\hline CA & $0.87(0.40-1.87)$ & 0.72 & - & - \\
\hline BA & $1.38(0.87-2.18)$ & 0.17 & - & - \\
\hline SMR-breast & $2.3(1.1-4.7)$ & 0.02 & $2.8(1.3-5.9)$ & 0.01 \\
\hline LH-basal & $0.95(0.56-1.59)$ & 0.84 & - & - \\
\hline LH-peak & $0.91(0.84-0.99)$ & 0.04 & $0.89(0.81-0.98)$ & 0.02 \\
\hline FSH-basal & $1.03(0.79-1.32)$ & 0.84 & - & - \\
\hline FSH-peak & $0.93(0.84-1.03)$ & 0.15 & - & - \\
\hline Estradiol & $1.01(0.99-1.02)$ & 0.11 & - & - \\
\hline LH-peak/FSH-peak & $0.61(0.34-1.12)$ & 0.11 & - & - \\
\hline
\end{tabular}

OR, odds ratio; $\mathrm{Cl}$, confidence interval; $\mathrm{CA}$, chronological age; $\mathrm{BA}$, bone age; SMR, sexual maturity rating; LH, luteinizing hormone; FSH, follicle-stimulating hormone. 


\section{Discussion}

Idiopathic CPP is the commonest form of precocious puberty girls and often results in adverse effects on both physical and psychological maturation. For this reason, an early diagnosis followed by immediate treatment is essential to improve both the physical and mental well-being of girls with precocity. Currently, an elevated GnRH-stimulated LH concentration is used to diagnose CPP; however GnRH stimulation test could be affected by multiple metabolic factors such as a degree of obesity. ${ }^{9}$

This study aimed to identify the effect of overweight on girls with CPP in terms of LH secretion. The 35 girls with overweight (15\%) had more advanced breast development than the normoweight. However, they did not display any remarkable difference in pubic hair development. The BMI $z$-score of overweight females was higher than that of the normoweight ones in this study. Accordingly, our study revealed two major findings: (1) overweight females have lower GnRH peaks and LH/FSH ratios after gonadorelin stimulation than those who are normoweight and (2) being overweight is negatively correlated with peak LH levels.

Our results support the conclusion drawn in previous studies that obesity and LH peak are correlated. Lee et al. ${ }^{2}$ investigated the effect of obesity on LH secretion in females with idiopathic CPP and described a positive association between increasing BMI and a diminished LH peak in the early pubertal stage. Pagán et al. ${ }^{10)}$ reported that LH, LH pulse amplitude, and LH response to gonadorelin were reduced in women with PCOS and that these variables were negatively correlated with BMI. In a study by Roth et al., ${ }^{11)}$ obese women had a lower LH response to gonadorelin stimulation compared to normoweight women.

There have been several explanations provided regarding the effect of overweight on LH. Insulin has been recognized as a key regulator of energy homeostasis through its brainmediated action. It also plays a role in regulating neural control of reproduction by affecting GnRH secretion. ${ }^{12)}$ An increase in obesity-related insulin resistance in obese individuals may interfere with sex hormone-binding globulin synthesis in the liver, leading to decreased estrogen inactivation. ${ }^{13,14)}$ This, in turn, leads to the sustained presence of unopposed estrogen in peripheral tissues. Moreover, obesity-related hyperinsulinemia increases the activity of aromatase by promoting and accelerating the conversion of serum testosterone into estrogen. ${ }^{15,16)}$ Elevated estrogen contributes to decreased sensitivity and feedback inhibition of the HPG axis. Combined, these mechanisms result in blunted $\mathrm{LH}$ responsiveness to gonadorelin stimulation.

The impact of overweight on LH secretion may also be associated with leptin. Leptin is a key molecular signal that controls food intake and energy balance via actions on multiple receptors located both centrally and peripherally. In subjects with increased levels of leptin including those with obesity, GnRH pulsatile release increases in frequency and promotes the onset of puberty, a mechanism that may be further exacerbated by leptin resistance. ${ }^{17,18)}$ Recent studies have described the contributions of exogenous adipokines (including leptin) to changes in GnRH pulsatile release, as these proteins also bind to leptin receptors in the hypothalamus. ${ }^{19)}$ The neurobiology of leptin signaling in obesity appears to involve an insufficiency in central leptin action, related to the previously described mechanism underlying central leptin resistance. ${ }^{20)}$

The present study has some limitations related to its cross-sectional, retrospective design and small sample size. Furthermore, our results examined only the effects of gonadotropins and estradiol, while other hormones, such as testosterone, insulin, and leptin, were not investigated. While our findings are consistent with those from previous studies, the present study lacks any mechanistic explanation for the inverse relationship between peak LH and excess body fat.

In conclusion, overweight peripubescent females, when compared to normoweight controls, are more likely to exhibit a lower LH peak after gonadorelin stimulation. Upon a diagnosis of precocious puberty (of any origin) in overweight or obese patients, therefore, we should consider the patient's obesity status as an influencing factor regarding the pubertal hormone concentration and the degree of obesity should be assessed during the evaluation of his or her sexual precocity. To better understand the role of obesity on gonadotropin secretion in precocious puberty, further research should explore the action of adipokinetic hormones and their receptors.

\section{Conflict of interest}

No potential conflict of interest relevant to this article was reported.

\section{References}

1. Carel JC, Léger J. Clinical practice. Precocious puberty. N Engl J Med 2008;358:2366-77.

2. Lee HS, Yoon JS, Hwang JS. Luteinizing hormone secretion during gonadotropin-releasing hormone stimulation tests in obese girls with central precocious puberty. J Clin Res Pediatr Endocrinol 2016;8:392-8.

3. Wang Y, Lobstein T. Worldwide trends in childhood overweight and obesity. Int J Pediatr Obes 2006;1:11-25.

4. Burt Solorzano CM, McCartney CR. Obesity and the pubertal transition in girls and boys. Reproduction 2010;140:399-410.

5. Barber TM, McCarthy MI, Wass JA, Franks S. Obesity and polycystic ovary syndrome. Clin Endocrinol (Oxf) 2006;65:137-45.

6. Poretsky L. Commentary: Polycystic ovary syndrome-increased or preserved ovarian sensitivity to insulin? J Clin Endocrinol Metab 2006;91:2859-60.

7. Moon JS, Lee SY, Nam CM, Choi JM, Choe BK, Seo JW, et al. 2007 Korean National Growth Charts: review of developmental process and an outlook. Korean J Pediatr 
2008;51:1-25.

8. Greulich WW, Pyle SD. Radiologic atlas of skeletal development of the hand and wrist. 2nd ed. Standford (CA): Standford University, 1959.

9. Suh J, Choi MH, Kwon AR, Kim YJ, Jeong JW, Ahn JM, et al. Factors that predict a positive response on gonadotropinreleasing hormone stimulation test for diagnosing central precocious puberty in girls. Ann Pediatr Endocrinol Metab 2013;18:202-7.

10. Pagán YL, Srouji SS, Jimenez Y, Emerson A, Gill S, Hall JE. Inverse relationship between luteinizing hormone and body mass index in polycystic ovarian syndrome: investigation of hypothalamic and pituitary contributions. J Clin Endocrinol Metab 2006;91:1309-16.

11. Roth LW, Bradshaw-Pierce EL, Allshouse AA, Lesh J, Chosich J, Bradford AP, et al. Evidence of GnRH antagonist escape in obese women. J Clin Endocrinol Metab 2014;99: E871-5.

12. Sliwowska JH, Fergani C, Gawałek M, Skowronska B, Fichna P, Lehman MN. Insulin: its role in the central control of reproduction. Physiol Behav 2014;133:197-206.

13. Kavanagh K, Espeland MA, Sutton-Tyrrell K, BarinasMitchell E, El Khoudary SR, Wildman RP. Liver fat and SHBG affect insulin resistance in midlife women: the Study of Women's Health Across the Nation (SWAN). Obesity
(Silver Spring) 2013;21:1031-8.

14. Pinkney J, Streeter A, Hosking J, Mostazir M, Jeffery A, Wilkin T. Adiposity, chronic inflammation, and the prepubertal decline of sex hormone binding globulin in children: evidence for associations with the timing of puberty (Earlybird 58). J Clin Endocrinol Metab 2014;99:3224-32.

15. Pauli EM, Legro RS, Demers LM, Kunselman AR, Dodson WC, Lee PA. Diminished paternity and gonadal function with increasing obesity in men. Fertil Steril 2008;90:346-51.

16. Pilia S, Casini MR, Foschini ML, Minerba L, Musiu MC, Marras V, et al. The effect of puberty on insulin resistance in obese children. J Endocrinol Invest 2009;32:401-5.

17. Baratta M. Leptin--from a signal of adiposity to a hormonal mediator in peripheral tissues. Med Sci Monit 2002;8:RA282-92.

18. Friedman JM, Halaas JL. Leptin and the regulation of body weight in mammals. Nature 1998;395:763-70.

19. Soliman AT, Yasin M, Kassem A. Leptin in pediatrics: a hormone from adipocyte that wheels several functions in children. Indian J Endocrinol Metab 2012;16(Suppl 3):S577-87.

20. Pan H, Guo J, Su Z. Advances in understanding the interrelations between leptin resistance and obesity. Physiol Behav 2014;130:157-69. 